\title{
Prólogo
}

\section{Camino al Bicentenario: optimismo y compromiso ante las crisis}

El año 2020 será recordado por la trágica pandemia de COVID-19 que paralizó al orbe, pero también por las complejas y múltiples crisis desatadas tanto en países en vías de desarrollo como en potencias globales. El Perú fue uno de los espacios más golpeados por la peste en el mundo; y lo que sufrió el sistema sanitario y nuestra gente lo sufrieron también la economía y el sistema político. No obstante, la sociedad peruana ha sabido hallar las vetas de luz para avanzar hacia la superación de la plaga, la recesión y la inestabilidad política y social.

Con ese mismo espíritu de hallar lo positivo en medio de la oscuridad, muchos han empezado a entender la importancia de la investigación científica y académica para el desarrollo del país, sobre todo en el campo de la ciencia y la tecnología. Evidentemente, la epidemia ha permitido tomar una mayor conciencia de la importancia de crear y consolidar una sociedad más avanzada sobre la base de los valores.

No olvidemos, sin embargo, que la ciencia por sí sola -es decir, sin la colaboración de las artes y humanidades- estaría mutilada 
de sus más altos fines. ¿Para qué más avances científicos y tecnológicos si no sirven para hacer el bien y para crear una humanidad más justa?

En la revista Aula Palma, que está próxima a completar su número 20, enarbolamos el espíritu investigativo, científico y humano. Pronto serán más de 500 artículos publicados en sus páginas, con el rigor académico, la originalidad crítica y el mensaje humano a partir de los asedios a la vida y obra de nuestro gran tradicionista don Ricardo Palma.

Fruto del trabajo inteligente y comprometido de los miembros de Número y Correspondientes del Instituto Ricardo Palma (IRP), el legado vital, literario, histórico y lingüístico de nuestro patrono no solo se ha consolidado como uno de los de mayor riqueza y valor sino también como uno de los más vigentes, pues en su afán de ir pintando cuadro por cuadro la historia peruana, Palma nos ha legado, entre multitud de sucesos peruanos, el registro de aquellos momentos en los que el país fue azotado por la naturaleza, lo que uno de los destacados miembros de nuestro Instituto, el doctor Lorenzo Huerta Vallejos, ha llamado las injurias del tiempo. Sin embargo, el escritor limeño no se queda en el dato histórico sazonado, sino va más allá y se atreve a enjuiciar a los personajes de la época. Estos juicios nunca se hacen solo desde una perspectiva política o exclusivamente sociohistórica; se hacen más bien, y sobre todo, desde un punto de vista humano. Y al hacerlo, revela las taras de los gobernantes y poderosos, pero también acusa a las clases populares sin dejar de mostrar las características positivas de nuestro pueblo, como el alegre optimismo que permitió que los peruanos superásemos infinidad de terremotos, pestes, guerras y malos gobiernos.

El presente número de la revista Aula Palma, el 19, es una nueva muestra del esfuerzo y el compromiso del IRP con la 
labor académica de alto nivel y con la reflexión y difusión del legado palmista, a pesar de la presente crisis sanitaria. Así, en esta edición aparecen los estudios de Oswaldo Holguín Callo sobre «Palma y Zorrilla»; el de Alberto Varillas Montenegro, «Palma y González Prada. Crónica de un distanciamiento»; el de Manuel Pantigoso, «Visión nocturna y luminosa del satírico Manuel Atanasio Fuentes 'El Murciélago'»; el de Carlos Alberto Pérez Garay, «Palma y las veladas literarias en la casa de Juana Manuela Gorriti: un espacio literario y de socialización en Lima (1876-1877)»; y el de Juan Carlos Adriazola Silva, «Clemente Palma en el afecto y la malquerencia de José de la Riva Agüero y Osma».

Otro conjunto de valiosas entregas asedian la figura de Palma desde diversas disciplinas y perspectivas críticas, como el trabajo de Luis Alberto Arista Montoya, «Ricardo Palma en el amanecer republicano»; el de Osmar Gonzales Alvarado, «Ricardo Palma y la cultura católica»; y el del maestro español Miguel Ángel Vega Cernuda, «Consideraciones lexicográficas a partir de las 'papeletas' de Ricardo Palma: por una lexicografía más inclusiva y por una mayor competencia léxica».

En el aporte de hallazgos que sobrepasan los linderos de lo nacional, están los artículos «Ricardo Palma, fabricante de tradiciones. Una reseña del crítico chileno Ernesto Montenegro (1924)», del también español Carlos Arrizabalaga; y «El deceso de Ricardo Palma en los periódicos de las Hemerotecas de la Biblioteca Pública de New York y de la Biblioteca del Congreso de los Estados Unidos de Washington D. C.», de Arnaldo Mera Ávalos.

Asimismo, hay investigaciones que analizan, precisan y comparan los textos de las propias tradiciones como «Edición crítica de las Tradiciones peruanas de Ricardo Palma», de Pedro Díaz Ortiz; «iCómo desvanecen los Comentarios reales de 'Carta canta' de Palma!», del norteamericano Thomas Ward; «Los 
derechos constitucionales y el ejercicio del poder por el general Salaverry en una tradición de Palma», del rector, fundador del Instituto, Iván Rodríguez Chávez; «Lima en las tradiciones peruanas de Ricardo Palma», de Marco Martos Carrera; «Un obispo de contrabando», de José Luis Ayala; «El pescado como alimento en el Perú virreinal», de César Coloma Porcari; «Ricardo Palma: Arte y estilo narrativo al reescribir sus relatos breves», de Eduardo Huárag Álvarez; y «Ricardo Palma, lector de Ventura Travada», de nuestro invitado César Félix Sánchez Martínez. Hallamos también artículos que exploran los otros géneros que extendieron el genio de nuestro escritor, como en «Palma y la poesía», de Eduardo Arroyo Laguna; y «Palma y Vallejo: complementariedad en la crítica literaria romántica», de Wellington Castillo Sánchez.

En vísperas de cumplirse el Bicentenario patrio, el Instituto Ricardo Palma, mediante su revista Aula Palma, honra y renueva su compromiso de seguir promoviendo la reflexión sobre la vida y obra del nuestro eximio escritor, ya sea mediante la continuación de renovadas líneas de investigación o a través de la inauguración de otras nuevas. Labor especialmente significativa en los tiempos que corren, pues la obra de Palma no solo nos muestra el pasado, sino que también nos abre los ojos frente al presente para avizorar, desde aquí, un futuro en donde por fin cumplamos uno de nuestros anhelos: lograr una patria con sólida identidad nacional que incluya los rasgos positivos y múltiples de nuestra diversidad cultural.

Expresamos nuestras sentidas condolencias por el fallecimiento de uno de nuestros miembros: el doctor Agustín de la Puente Candamo, acaecido el 5 de febrero de este año. Autor de notables obras sobre la historia del Perú, el maestro de la Puente Candamo deja una huella imperecedera que siempre nos ha de orientar. 